\title{
Comparison of urinary 5-L-oxoproline (L-pyroglutamate) during normal pregnancy in women in England and Jamaica
}

\author{
BY ALAN A. JACKSON ${ }^{1}$, CHANDARIKA PERSAUD ${ }^{1}$, \\ GEOFF WERKMEISTER ${ }^{2}$, IRENE S. M. MCCLELLAND ${ }^{1}$, \\ ASHA BADALOO ${ }^{3}$ AND TERRENCE FORRESTER ${ }^{3}$ \\ ${ }^{1}$ Institute of Human Nutrition, University of Southampton, Bassett Crescent East, \\ Southampton SO16 7PX \\ ${ }^{2}$ Department of Obstetrics and Gynaecology, University of Southampton, Princess Anne Hospital, \\ Coxford Road, Southampton SO16 5YA \\ ${ }^{3}$ Tropical Metabolism Research Unit, University of the West Indies, Mona, Kingston 7, Jamaica
}

(Received 27 February 1996 - Revised 3 June 1996 - Accepted 8 July 1990)

\begin{abstract}
Urinary 5-L-oxoproline was measured during normal pregnancies in Southampton, England and Kingston, Jamaica. The $\mathrm{CV}$ of 5-L-oxoproline excretion in urine, determined over $7 \mathrm{~d}$ in a nonpregnant woman and three pregnant women, was 10-36\%. Compared with non-pregnant women, urinary 5-L-oxoproline increased three to four times from early pregnancy in women in Southampton, a highly significant difference, and remained elevated at similar levels during mid and late pregnancy. For women in Kingston, the excretion of 5-L-oxoproline was similar to that of Southampton women in the non-pregnant group and during early pregnancy. However, there was a progressive increase in the excretion of 5-L-oxoproline as pregnancy advanced and by late pregnancy excretion was from three to ten times greater than the average for the non-pregnant women. There was a significant difference between the women in Southampton and the women in Kingston during mid and late pregnancy, with women in Kingston excreting twice as much 5-Loxoproline during late pregnancy. If the excretion of 5-L-oxoproline is a measure of glycine insufficiency, the results would indicate that in some pregnancies the ability of the mother to provide glycine for herself and the developing fetus is marginal or ingdequate and the constraint appears more marked in Jamaica than in England.
\end{abstract}

Glycine: 5-L-Oxoproline: Amino acids: Pregnancy

During pregnancy complex changes in the physiological partitioning of nutrients are required to enable the growth and development of the fetus, remodelling of maternal tissues to carry the pregnancy and the deposition of reserves in anticipation of lactation. There is the need for an increase in the amount of nutrients and also a shift in the pattern of specific nutrients required if these changes are to be satisfied appropriately. The total protein accumulated over pregnancy is estimated to be $925 \mathrm{~g}$ in a women gaining $12.5 \mathrm{~kg}$ weight and giving birth to a healthy infant weighing $3.5 \mathrm{~kg}$ (Hytten \& Chyne, 1971). Although the total change might appear quite large, on a daily basis the increments are relatively small, $50 \mathrm{mg}$ protein $/ \mathrm{kg}$ per $\mathrm{d}$, and at the limit of the sensitivity of most methods available for their measurement. The recommended intake of protein for pregnancy is based on a limited set of data and we have even less understanding of the changes in the qualitative needs (Food and Agriculture Organization/World Health Organization/ United Nations University, 1985). Classical balance methods are not well suited for 
measuring small changes over relatively long periods of time and insights have been sought by the application of more dynamic measures such as protein turnover and urea kinetics.

In Jamaican women measures of protein synthesis show a high rate of synthesis early in pregnancy which falls towards levels similar to the non-pregnant state by late pregnancy (de Benoist et al. 1985). This contrasts with results in the UK where protein synthesis remains relatively unchanged throughout pregnancy (Thompson \& Halliday, 1992). It is not clear whether the different results in the two populations represent real differences in physiology, or are a reflection of the use of different methods in the two studies. However, when the same method is used to measure urea kinetics in women from England and Jamaica a similar pattern of difference is also observed. Women in Jamaica have an increase in the rate of urea salvage during early pregnancy which falls towards the nonpregnant rate as pregnancy progresses (Forrester et al. 1994). By contrast in England the changes in urea salvage at different stages of pregnancy are much more modest with the most intense salvage of urea- $\mathrm{N}$ seen at approximately week 24 of pregnancy (McClelland et al. 1997).

The demands for protein and amino acids for maintenance are very different from the demands for growth and net deposition. For example, the demands for specific amino acids by the fetus are very uneven, relating to the development of metabolic pathways for the synthesis of specific amino acids, for example cysteine, and the irregular amounts of amino acids needed for a particular pattern of tissue growth and deposition. In the late fetal and newborn periods the estimated imbalance between the needs of the offspring and the supply or availability of amino acids from breast milk is most marked for glycine (Widdowson et al. 1979). There is a particularly high demand for glycine by the fetus as pregnancy progresses, and in relative terms this might be anything from two to ten times that for any other amino acid on a molar basis (Widdowson et al. 1979). The need for increased amounts of collagen and elastin for the growth of extracellular tissues such as bone and connective tissue means that the requirement for glycine especially is increased. Similarly glycine is required in increased amounts for the synthesis of bile salts, purines, porphyrins, creatine and glutathione (Jackson, 1991). Glycine and serine are readily interchangeable and both are generally considered to be non-essential amino acids in the diet (Arnstein, 1952; Neuberger, 1981; Laidlaw \& Kopple, 1987). However, as in the young rat (Arnstein, 1952), there is the real possibility that during early rapid growth in the human subject, the ability of endogenous synthesis to supply sufficient glycine may not always satisfy the metabolic demand (Jackson et al. 1981; Jackson, 1991). It is not possible to measure directly the balance between the demand for glycine and the available supply. However, we have found that the urinary excretion of 5-L-oxoproline is increased when the glycine pool of the body is specifically depleted (Jackson et al. 1987) and in situations where the demand for glycine is expected to be high (Jackson, 1991; Fig. 1).

In an earlier study we measured 5-L-oxoproline in the urine of Jamaican women at three different stages of pregnancy in a cross-sectional study (Persaud et al. 1989). There is a progressive increase in urinary 5-L-oxoproline as pregnancy advances, reaching very high levels during late pregnancy. Furthermore, there is wide variability in the excretion of 5-Loxoproline between different women. In the present study we have sought to answer three questions. First, the extent of the daily variability in 5-L-oxoproline excretion in individual women during pregnancy. Second, whether the pattern of excretion of urinary 5-Loxoproline in pregnant women in England is similar to that seen in Jamaica. Third, whether the pattern of change seen in the cross-sectional study is also seen when repeat measures are made in the same women at different times during pregnancy. 


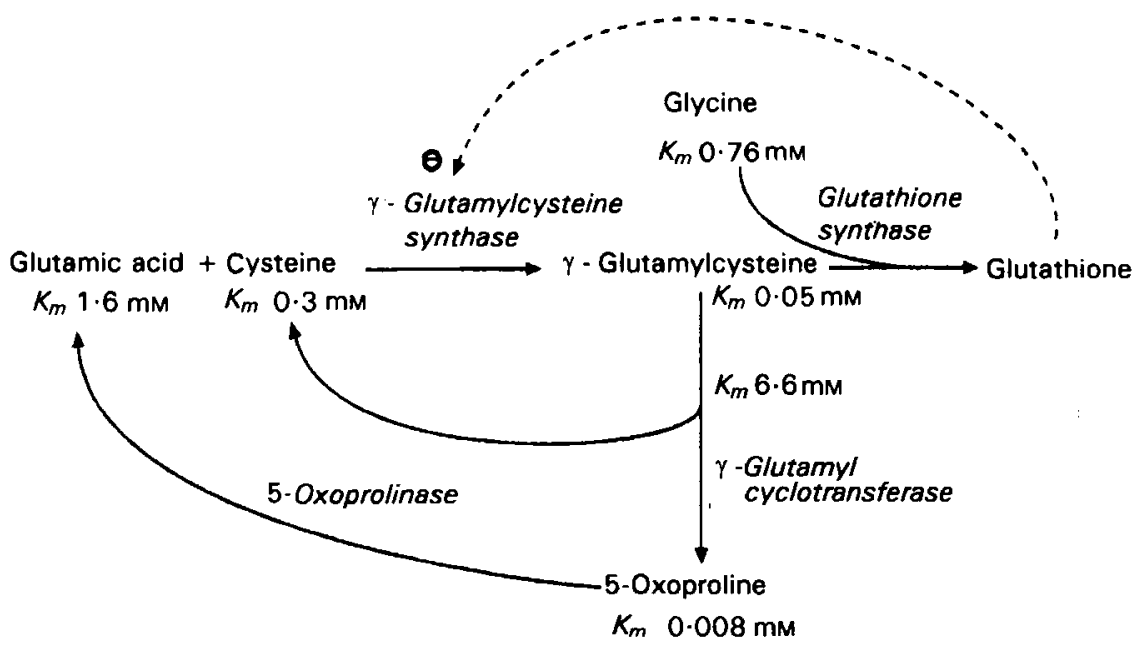

Fig. 1. Glutathione, $\gamma$-glutamylcysteinylglycine, is synthesized in two steps catalysed by glutamate-cysteine ligase ( $\gamma$-glutamylcysteine synthase; $E C$ 6.3.2.2), and glutathione synthase (EC 6.3.2.3). Glutathione exerts feedback inhibition on $\gamma$-glutamylcysteine synthase so that in the congenital absence of glutathione synthase, excess $\gamma$ glutamylcysteine is cleaved by $\gamma$-glutamyl cyclotransferase $(E C 2.3 .2 .4)$ to give 5-L-oxoproline, which can be converted to glutamic acid by 5-L-oxoprolinase (EC 3.5.2.9). Benzoic acid is conjugated with glycine to form hippuric acid which is excreted in urine. When a large oral load of sodium benzoate is given the glycine pool is drained and the availability of glycine for glutathione formation is constrained, resulting in increased excretion of 5-L-oxoproline in urine (Jackson et al. 1987).

\section{METHODS}

The study had the approval of the Joint Ethical Committee of Southampton University and South West Hampshire Health Authority and the ethical committee of the University Hospital of the West Indies. All the women who participated gave their consent after the nature of the study had been explained and they were advised that they were free to withdraw at any time without prejudice. Four protocols were followed during which urine was collected for periods of $24 \mathrm{~h}$, and preserved in $6 \mathrm{M}-\mathrm{HCl}(250 \mu \mathrm{l})$. After the volume of each $24 \mathrm{~h}$ urine sample had been measured a portion was stored frozen at $-4^{\circ}$ until required for analysis. The urine was analysed for 5-L-oxoproline and creatinine.

\section{Protocol 1}

The objective of this study was to establish the day-to day variability in the excretion of urinary 5-L-oxoproline in the non-pregnant state and at different stages of pregnancy. The study was carried out in four women, one of whom was not pregnant and three who were pregnant at 20,24 and 32 weeks of gestation respectively. Each woman collected sequential $24 \mathrm{~h}$ samples of urine over a period of $7 \mathrm{~d}$. During the study the subjects were asked to maintain their habitual diet and lifestyle.

\section{Protocol 2}

The objective of this study was to measure urinary 5-L-oxoproline at different stages of normal pregnancies in women in Southampton. Eighty-eight women at different stages of pregnancy were studied in a cross-sectional design. The women were attending the 
antenatal clinic of the Princess Anne Hospital, Southampton and had uncomplicated medical histories. Samples $(24 \mathrm{~h})$ of urine were collected at different stages during pregnancy. For comparative purposes the women were divided into three groups; thirty-one women at up to week 16 of gestation, nineteen women at between weeks 16 and 27 of gestation, and thirty-eight women who were beyond week 28 of gestation. The results were compared with $24 \mathrm{~h}$ samples of urine collected from twenty non-pregnant women. The heights and weights of the mothers and the weight of the infant at birth were obtained from hospital notes.

\section{Protocol 3}

The objective of this study was to compare the excretion of 5-L-oxoproline in urine throughout pregnancy in women in Southampton in a longitudinal study. The opportunity was taken to measure 5-L-oxoproline in the urine of women who had collected urine at different stages of pregnancy (McClelland et al. 1996). Nine women were recruited from the antenatal clinic of the Princess Anne Hospital in Southampton. Each woman provided a $24 \mathrm{~h}$ sample of urine at three different stages during pregnancy: weeks 16,24 and 32 . The recorded birth weights of the infants were obtained from hospital notes. The height and weight of each mother was recorded.

\section{Protocol 4}

In a cross-sectional study of 5-L-oxoproline excretion during pregnancy of women in Kingston, Jamaica, the method used for measuring 5-L-oxoproline in urine was different in detail from that used in the present study (Persaud et al. 1989), raising the possibility that any differences observed between the two groups of women might be attributed to differences in the method. Thus, comparative data were obtained from a longitudinal study being conducted in Kingston (Forrester et al. 1994). In nine pregnant women, $24 \mathrm{~h}$ samples of urine were collected at three different stages of pregnancy: weeks 12,24 and 32 . The women had uncomplicated medical histories and were attending the antenatal clinic of the University Hospital of the West Indies, Jamaica. Non-pregnant women from the nursing and scientific staff provided a $24 \mathrm{~h}$ sample of urine for comparative purposes. The height and weight of each subject was measured and the weights of the infants at birth obtained from the hospital notes.

All the women in Southampton were Caucasian and all the women in Jamaica were of African descent.

\section{Biochemical analyses}

Urinary 5-L-oxoproline was measured by a modification of the method of van der Werf et al. (1974). This approach ensures that 5-L-oxoproline is measured without any contamination from 5-D-oxoproline which may be present in the diet or produced by the colonic microflora. 5-Oxoproline was isolated by short-column ion-exchange chromatography, free from glutamate and other amino acids. The 5-L-oxoproline in the eluate was hydrolysed in hot acid to glutamic acid (McPherson \& Slater, 1959) and the resulting Lglutamic acid measured enzymically with glutamate dehydrogenase (EC 1.4.1.2; Lund, 1984); for details, see Jackson et al. (1996). Creatinine in the urine was measured by the alkaline picrate method of Jaffe as described by Bonsnes \& Taussky (1945), after pretreatment of the urine with Lloyd's reagent to remove interfering chromogens. 


\section{Statistical analysis}

The data are expressed as the mean and $95 \% \mathrm{CI}$. Sets of data were compared using ANOVA and post hoc $t$ tests. Unpaired $t$ tests were used to detect differences between study groups. A value for $P<0.05$ on a two-tailed test was accepted as statistically significant.

\section{RESULTS}

\section{Within-person variability}

In Table 1 the excretion of 5-L-oxoproline in urine over $7 \mathrm{~d}$ in one non-pregnant woman and three pregnant women is shown. The variability in excretion was $10-36 \%$, which was not reduced when expressed in relation to body weight or the urinary excretion of creatinine. The variability was greater in the women who had been pregnant for 24 and 32 weeks than the non-pregnant woman or the woman at 20 weeks of gestation, however, the basis for this variability is not known. There was no statistical difference in excretion between the non-pregnant woman and the pregnant women at week 10 or week 24 , but the difference was significant for the woman at week 32 .

\section{Cross-sectional study of pregnant women in Southampton}

Table 2 shows the characteristics of the women in the cross-sectional study in Southampton. The women studied in early, mid and late pregnancy were of similar age and height and gave birth to infants of similar weight on average. The mean stage of gestation for the three groups of women were: 10 weeks ( $n 31) 17$ weeks $(n 19)$ and 34 weeks $(n 38)$. There was a highly significant difference in 5-L-oxoproline excretion for each group of pregnant women when compared with the non-pregnant women, but there were no differences between the three groups of pregnant women at early mid and late pregnancy.

Factors which might relate to the variability in 5-L-oxoproline between individuals were sought by linear regression analysis. There were no relationships identified between urinary 5-L-oxoproline and gestational age, infant birth weight or maternal height. However, there was a significant relationship between urinary 5-L-oxoproline and matemal

Table 1. Urinary 5-L-oxoproline was measured in seven consecutive, 24 h collections of urine in one non-pregnant woman and in three pregnant women at 20,24 and 32 weeks gestation respectively§

\begin{tabular}{|c|c|c|c|c|}
\hline \multirow{2}{*}{$\begin{array}{l}\text { Status of subject... } \\
\text { 5-Oxoproline }\end{array}$} & \multirow[b]{2}{*}{ Non-Pregnant } & \multicolumn{3}{|c|}{ Stage of pregnancy } \\
\hline & & 20 weeks & 24 weeks & 32 weeks \\
\hline \multicolumn{5}{|l|}{$\mu \mathrm{mol} / \mathrm{d}$} \\
\hline Mean & 147 & 173 & 209 & $341 * * * \dagger+\ddagger \ddagger$ \\
\hline $95 \% \mathrm{Cl}$ & $131-163$ & $160-186$ & $158-260$ & $247-435$ \\
\hline $\mathrm{CV}$ & 14 & 10 & 33 & 36 \\
\hline \multicolumn{5}{|l|}{$\mu \mathrm{mol} / \mathrm{mmol}$ creatinine } \\
\hline Mean & 14 & 17 & $38 * * *+\dagger$ & $37 * * *+\dagger$ \\
\hline $95 \% \mathrm{Cl}$ & $12-16$ & $15-19$ & $28-48$ & $28-49$ \\
\hline $\mathrm{CV}$ & 21 & 17 & 34 & 32 \\
\hline \multicolumn{5}{|c|}{$\mu \mathrm{mol} / \mathrm{kg}$ body wt per $\mathrm{d}$} \\
\hline Mean & 2.9 & 3.0 & 3.4 & $5 \cdot 3 * * * t+t t$ \\
\hline $95 \% \mathrm{Cl}$ & $2 \cdot 8-3 \cdot 1$ & $2.7-3.3$ & $2.9-4.7$ & $3.9-6.8$ \\
\hline CV & 7 & 13 & 36 & 37 \\
\hline
\end{tabular}

Mean values were significantly different from those for non-pregnant woman: $* * * P<0.001$.

Mean values were significantly different from those for week $20: \dagger+P<0.01$.

Mean values were significantly different from those for week 24 : $\ddagger \ddagger P<0.01$.

$\S$ For details of subjects and procedures, see pp. 185-187. 


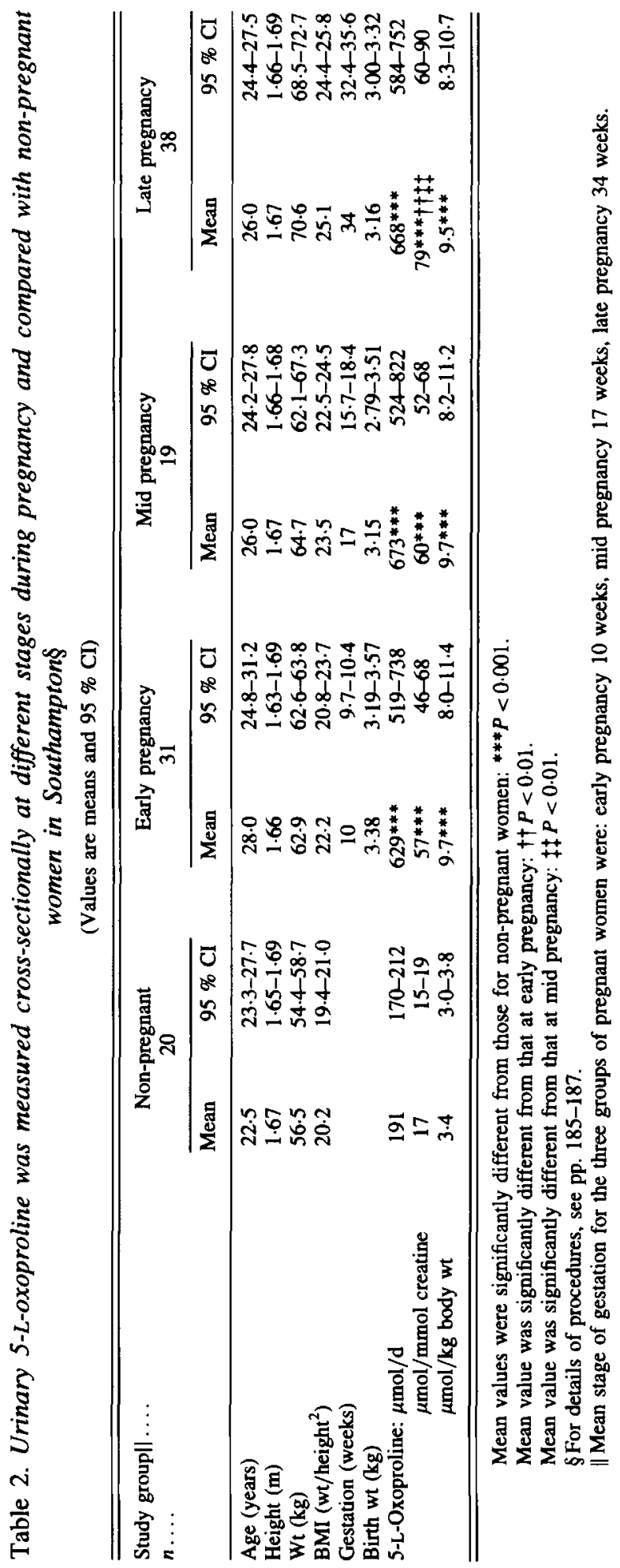




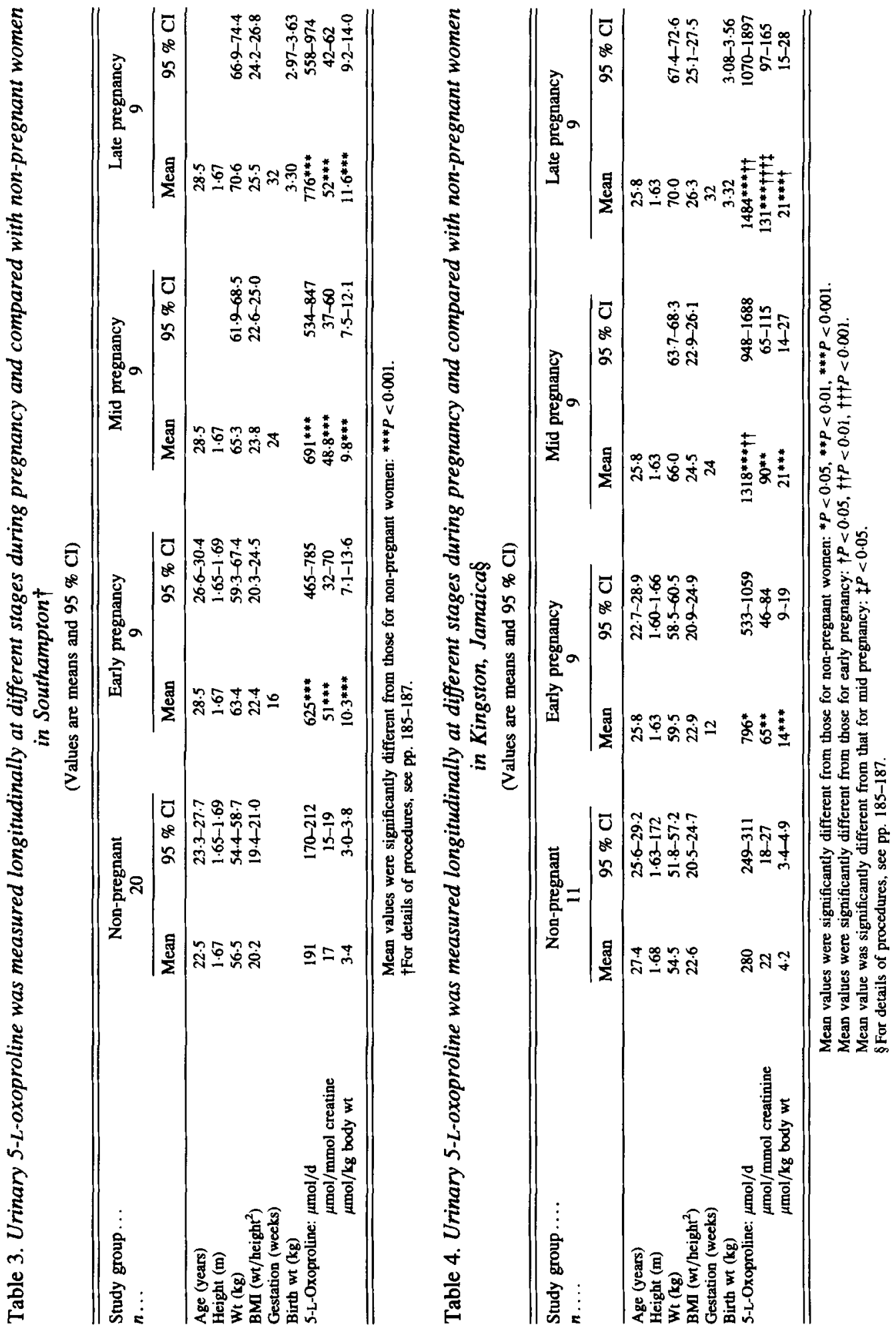


BMI ( $r 0.29, P=0.007)$ and maternal weight $(r 0.29, P=0.007)$ for the entire group. In mid pregnancy there was a strong relationship between 5-L-oxoproline and maternal BMI and weight (both $r 0.9, P<0.0001$ ), heavily influenced by one overweight woman, but not during early or late pregnancy.

\section{Longitudinal study of pregnant women in Southampton}

Table 3 shows the characteristics of the women in Southampton who were studied longitudinally throughout pregnancy. There was no statistical difference in the excretion of 5-Loxoproline in urine at weeks 16,24 and 32. However, at each time point urinary 5-Loxoproline was significantly greater than that of the non-pregnant women. There were no differences in the excretion of 5-L-oxoproline between the women in the cross-sectional study

(a) Cross-sectional study
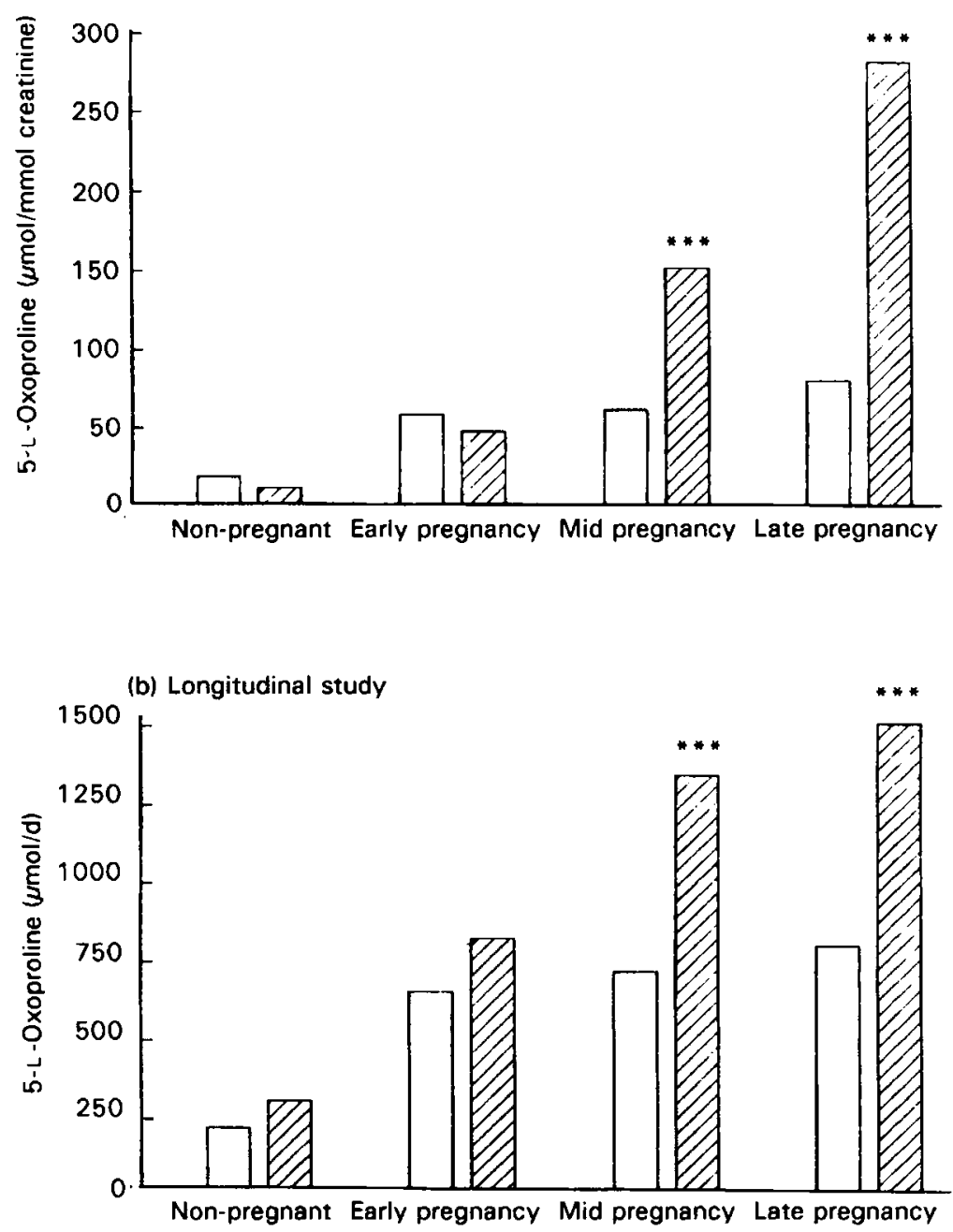

Fig. 2. The urinary excretion of 5-L-oxoproline was measured in non-pregnant women and pregnant women during early, mid and late pregnancy in (a) a cross-sectional and (b) a longitudinal study in Southampton, England ( $\square$ ) and in a longitudinal study in Kingston, Jamaica (荡). The cross-sectional data for Kingston, Jamaica are taken from Persaud $e t$ al. (1989). Mean values for Kingston women were significantly different from those for Southampton women: $* * * P<0.001$. 
and the women in the longitudinal study. For both groups 5-L-oxoproline excretion was increased between three and four times compared with the non-pregnant women. There was a difference between the non-pregnant women and pregnant women during late pregnancy when 5-L-oxoproline was expressed relative to creatinine excretion $(P<0.01)$. It is clear that the range of excretion varies considerably amongst women and at each stage of pregnancy there were some women in whom urinary excretion of 5-L-oxoproline was similar to the excretion in non-pregnant women, while others excreted ten times more than the non-pregnant women.

There was no relationship between urinary 5-L-oxoproline and gestational age, weight of the infant at birth, maternal weight, maternal height, or maternal BMI.

\section{Longitudinal study of pregnant women in Kingston}

The characteristics of the women studied longitudinally throughout pregnancy in Kingston are shown in Table 4. At each stage of pregnancy the excretion of 5-L-oxoproline was greater than that in the non-pregnant state; about threefold at week 12 and fivefold at weeks 24 and 32 and these differences were highly statistically significant. Furthermore, there was a progressive increase in excretion as pregnancy advanced, thus excretion at weeks 24 and 32 was significantly greater than excretion at week 12 . By week 32 all pregnant women excreted more 5-L-oxoproline than the non-pregnant women, from three to ten times the average for the non-pregnant state.

There was no relationship between urinary 5-L-oxoproline and birth weight, maternal weight, maternal height or maternal BMI.

\section{Comparison of pregnant women in Southampton and Kingston}

In the longitudinal studies, women in Kingston were a little shorter than those in Southampton, but there was no difference in age, weight, BMI or birth weight between the two groups. The pattern of excretion of 5-L-oxoproline for the two groups of women is shown in Fig. 2 for the longitudinal and cross-sectional studies and for the cross-sectional study is compared with the data from Persaud et al. (1989). For the non-pregnant women there was no statistical difference in urinary 5-L-oxoproline between Kingston and Southampton. For the pregnant women there were no differences in urinary 5-L-oxoproline in early pregnancy nor in creatinine excretion between the groups at any stage (data not shown). There was a consistent difference in urinary 5-L-oxoproline between women in Kingston and Southampton in mid and late pregnancy $(P<0.001)$, however expressed. During early pregnancy excretion of 5-L-oxoproline on a per $\mathrm{kg}$ body weight per $\mathrm{d}$ basis was significantly greater in Kingston than in Southampton, but as this represents a comparison between week 12 and week $16(P<0.01)$ the difference is attributed to differences in body weight. By late pregnancy there was a twofold difference in urinary 5L-oxoproline between Kingston and Southampton.

\section{DISCUSSION}

The data in the present study have shown that increased 5-L-oxoprolinuria was a usual feature of pregnancy in both Kingston and Southampton. It was found early in pregnancy before significant changes in maternal and fetal size were evident, during mid pregnancy when rates of nutrient storage in maternal tissue were at a maximum, and late pregnancy when fetal growth was at its greatest. The cross-sectional studies for women in Southampton and Kingston have shown that as early as 10 weeks of gestation 5-L-oxoproline had increased to three to four times the excretion in non-pregnant women on average. This high rate of excretion was maintained at a similar level throughout pregnancy in Southampton, but increased progressively as pregnancy advances in Kingston (Persaud et al. 1989). There was 
wide variability in excretion in non-pregnant women and in women at every stage of pregnancy in both locations. That these were not chance observations related to subject selection was shown in the longitudinal studies, where it was found that the pattern of change in the same women at different stages of pregnancy followed the pattern observed in the cross-sectional studies. The data raise the question whether the increased 5-L-oxoprolinuria was an unremarkable part of the physiological adjustment to the pregnant state, or the extent to which, in some women at least, it might have been indicative of a perturbed metabolic state. There are three important issues which need to be addressed. First, the reason for an increase in urinary 5-L-oxoproline of such magnitude during pregnancy. Second, the reason for the distinct difference in the pattern of excretion of 5-L-oxoproline between Kingston and Southampton. Third, the reason for the wide variation in excretion in individual women and for different women in an apparently similar environment.

Renal function changes as part of the general physiological response to pregnancy and these changes include an alteration in the way in which amino acids are handled. There are alterations in the glomerular filtration rate and reduction in the efficiency of tubular reabsorption which lead to an increase in the renal loss of most amino acids, with the extent varying from one amino acid to another. For most amino acids there may be a doubling in the rate of excretion, with the maximal change being six to eight times normal rates (Wallraff et al. 1950; Hytten \& Chyne, 1971). The urinary excretion of creatinine tends to increase also as gestation advances and there is normally an increase in maternal weight. As a consequence of these changes, although the absolute rate of amino acid excretion may increase, the relative rate of excretion remains fairly constant or falls when expressed relative to body weight or urinary creatinine. Compared with the non-pregnant women, the excretion of 5-L-oxoproline was significantly increased in all groups of pregnant women when expressed relative to urinary creatinine or body weight. Therefore, although the changes in renal function might account for a part of the increase in urinary 5-L-oxoproline in pregnancy, it seems unlikely that this can be the basis for all the change, or the variability between individuals, and certainly cannot account for the difference between the two locations.

The most common reason for an increase in the urinary excretion of 5-L-oxoproline is the presence of a congenital deficiency of either the enzyme glutathione synthase ( $E C$ 6.3.2.3) or 5-L-oxoprolinase (EC 3.5.2.9; Meister, 1974; Larsson, 1981). Infants with these conditions excrete on average 9-25 mmol 5-L-oxoproline/d. In the pregnant woman the highest values were seen in the third trimester, an average of $0.7-1.5 \mathrm{mmol} / \mathrm{d}$, but reached a maximum value of $3 \mathrm{mmol} / \mathrm{d}$. Under normal circumstances the capacity of both enzymes greatly exceeds the level of the activity required for normal function (van der Werf \& Meister, 1975), suggesting that constraints on either enzyme are unlikely to be the basis for the increase in excretion observed. Indeed, in the rat both fetal and maternal tissues develop an enhanced capacity to synthesize glutathione as pregnancy advances (di Ilio et al. 1985, 1986). Increases in 5-oxoprolinuria, presumed to derive from D-glutamate, have been associated with an increase in dietary intake, or excessive production by the colonic bacteria (Oberholzer et al. 1975; van der Werf \& Meister, 1975). In these circumstances the increase is in 5-D-oxoprolinuria. The enzyme assay used in the present study was specific for 5-L-oxoproline, the increased excretion of 5-L-oxoproline is unlikely to arise either from a dietary or bacterial source. Whereas oral 5-D-oxoproline is recovered quantitatively in urine, with large oral doses of 5-L-oxoproline none is recovered in urine, but there is urinary recovery when administration is intravenous (Chmielewska et al. 1967). In rat studies 5-D-oxoproline is not retained in the system but excreted. In contrast, 5-L-oxoproline is rapidly and effectively metabolized by 5-L-oxoprolinase which is widely distributed in tissues (Ramakrishna et al. 1970). Hence, even though many secreted 
proteins have 5-L-oxoproline formed at the $\mathrm{N}$-terminus as a late translational or posttranslational event (Abraham \& Podell, 1981), the capacity of 5-L-oxoprolinase is adequate to handle this physiological load (van der Werf \& Meister, 1975).

Apart from inborn errors of metabolism, an increase in urinary 5-L-oxoproline is only regularly and reproducibly identified in situations where an agent is given which, through conjugation with endogenous glycine, leads to depletion of the glycine pool in the body. Large amounts of 5-L-oxoproline are normally produced as an intermediary in the $\gamma$-glutamyl cycle (van der Werf \& Meister, 1975; Fig. 1). Glutathione exerts feedback control on its own formation, to decrease the rate of synthesis of $\gamma$-glutamylcysteine. With a congenital absence of glutathione synthase, glutathione concentrations are low and the rate of formation of $\gamma$ glutamylcysteine is increased, but it cannot be further metabolized to glutathione. Under these circumstances it follows an alternative metabolic route, being hydrolysed to cysteine and 5-L-oxoproline, through internal cyclization of the glutamic acid. Excessive production of 5-L-oxoproline exceeds the capacity of 5-L-oxoprolinase, resulting in accumulation in plasma and renal overflow. A limitation in the availability of glycine, the other substrate for glutathione synthase, can lead to a similar result, 5-L-oxoprolinuria (Jackson et al. 1987). Sodium benzoate is excreted as hippuric acid following conjugation with glycine (Quick, 1931). In normal adults an oral dose of 4-10 g sodium benzoate leads to 5-L-oxoprolinuria which is reversed when a dietary supplement of glycine is provided to enable the formation of hippuric acid (Jackson et al. 1987). In children treated with sodium benzoate for disorders of the urea cycle, the highest dose which can be given without side effects is determined by the available glycine and toxic levels are associated directly with an increase in urinary 5-Loxoproline (Shinka et al. 1985). In rats treated with benzoic acid there is an increase in urinary 5-L-oxoproline (Shinka et al. 1985), and 5-oxoprolinuria has been found in human subjects and rats treated with high doses of paracetamol or vigabatrin (Bonham et al. 1989; Pitt 1990; Pitt et al. 1990; Persaud \& Jackson, 1991; Ghauri et al. 1993). Therefore, the possibility arises that the increased 5-L-oxoproline seen in pregnancy is related to a perturbation of glycine metabolism.

The endogenous formation of glycine has not been measured in pregnant women, but the rate of formation in adults and children has been found to be between 200 and $250 \mu \mathrm{mol} / \mathrm{kg}$ per h (Jackson, 1991) and appears to fall with age (Gersovitz et al. 1980). When fasted or on intakes low in protein or amino acids there is a reduction in the rate of endogenous formation in adults to levels below that needed to satisfy normal metabolism (Gersovitz et al. 1980; Yu et al. 1985; Jackson, 1991). In normal adults urinary 5-Loxoproline increases in direct proportion to a decrease in dietary $\mathrm{N}$ or protein (Jackson $e t$ al. 1996). The protein intake of the non-pregnant women in the present study was approximately 70-75 $\mathrm{g} / \mathrm{d}$, and ranged from $80-85 \mathrm{~g} / \mathrm{d}$ in early pregnancy to $85-95 \mathrm{~g} / \mathrm{d}$ for mid and late pregnancy. The differences between Kingston and Southampton were relatively small and, therefore, the glycine intake between the two locations is likely to have been similar (Forrester et al. 1994; McClelland \& Jackson, 1996; McClelland et al. 1997) and could not account for the differences in 5-L-oxoproline excretion observed (Jackson et al. 1996). It has not been possible to determine with reliability the rate at which glycine moves to a range of metabolic pathways for which the need is large, and in the short term buffering might take place through a limitation in the formation of one or other product, e.g. creatine, haem or glycine-conjugated bile salts.

Some women change the kind or amount of food that is eaten during pregnancy and there is often the development of unusual aversions or cravings (Taggart, 1977; Landman $\&$ Hall, 1988). The pattern of food intake and food habits of women in Kingston and Southampton is undoubtedly different and may account for some of the differences seen in 
5-L-oxoproline. Benzoate is found naturally in fruits and is a preservative in the food industry. Consumption of large quantities of foods containing benzoate will utilize increased amounts of glycine and could lead to an increase in 5-L-oxoproline excretion. In the Jamaican population the consumption of 'bush teas' is popular, especially during pregnancy (Landman \& Hall, 1988) and the need to excrete the alkaloids in the plants could theoretically add to a drain on glycine metabolism. Simple calculations indicate that although these effects might account for a part of the variation between individuals, it is very unlikely that the differences between non-pregnant and pregnant women can be explained on this basis, nor can the considerably increased excretion found in Jamaica.

Glycine and serine are closely related metabolically and their interconversion depends on the availability of tetrahydrofolate. In folic acid deficiency the rate of glycine biosynthesis, as well as the glycine-serine interconversion, is greatly decreased (Amstein \& Stankovic, 1956). The need for folic acid increases during pregnancy, especially with the increased needs for maternal erythropoiesis and fetal and placental growth (Hubbard, 1964; Kitkay \& Harbot, 1975), and increased quantities of folate degradation products can be recovered in the urine (McPartlin et al. 1991). The reference nutrient intake for folic acid is set at $200 \mu \mathrm{g} / \mathrm{d}$ (Committee on Medical Aspects of Food Policy, 1991); however, since supplemental folic acid in the periconceptual period has been shown to reduce the risk of neural-tube defects (MRC Vitamin Study Research Group, 1991) an additional $400 \mu \mathrm{g} / \mathrm{d}$ folic acid is advised for women who are planning a pregnancy (Department of Health, 1992). This suggests the possibility that from early in pregnancy glycine-serine interconversion might be compromised. Up to $20 \%$ of women have low levels of serum folate during an otherwise normal pregnancy (Herbert et al. 1975) and $6.2 \%$ of British women not taking a folic acid supplement show a decrease in serum folate (Chanarin et al. 1968).

Folate deficiency is much more evident during late pregnancy, coinciding with the time when demands are greater. In pregnant Jamaican women, 5-L-oxoproline increased most during late pregnancy. Although it has been suggested, on the basis of dietary recall data, that folate intake during pregnancy in Jamaican women is adequate, this presumes that significant amounts had not been lost during cooking (Herbert et al. 1975; Hall, 1992). In the aftermath of Hurricane Gilbert, which hit Jamaica in 1989, the incidence of neuraltube defect increased and there was an increase in low folate levels in routine haematological investigations (Duff et al. 1991). It was estimated that folate intake fell from marginal to inadequate with dependency on emergency rations (Duff \& Cooper, 1994). One further difference between the two groups is the level of exposure to sunlight. It has been postulated that exposure to u.v. light can give rise to folate depletion through cutaneous photolysis, with a measure of protection being afforded by skin pigmentation (Branda \& Eaton, 1978; Jablonski, 1992).

A generalized amino aciduria cannot explain differences in the excretion of 5-Loxoproline in urine between Jamaica and England, or the wide difference between individual women, or at different stages of pregnancy. Circumstantial evidence suggests that the 5-L-oxoprolinuria relates to a shortfall in the availability of glycine, through a constraint on biosynthesis. If the excretion of urinary 5-L-oxoproline is directly related to a marginal glycine status the results suggest that for some pregnancies the ability of the mother to provide adequate glycine for herself and the developing fetus was inadequate and the constraint was more evident in Jamaica than in England.

We have already identified that measures of protein synthesis during pregnancy in Jamaican women are very different to those seen in women in England (de Benoist et al. 1985; Thompson \& Halliday, 1992) and that there are similar differences when urea kinetics are measured in pregnancy in the two locations (Forrester et al. 1994; McClelland 
et al. 1996). We have now identified a consistent difference in the urinary excretion of 5-Loxoproline. Together these results indicate that the handling of protein, amino acids and $\mathrm{N}$ during pregnancy is different between the two locations and the basis of this difference needs to be determined.

We are grateful for support from Birthright (Wellbeing), Medical Research Council, Nestlé Nutrition Research Grant Fund and the Wellcome Trust.

\section{REFERENCES}

Abraham, G. N. \& Podell, D. N. (1981). Pyroglutamic acid: non-metabolic formation, function in proteins and peptides, and characteristics of the enzyme effecting its removal. Molecular and Cellular Biochemistry 38 , 181-190.

Arnstein, H. R. V. (1952). The metabolism of glycine. Advances in Protein Chemistry 9, 1-91.

Arnstein, H. R. V. \& Stankovic, V. (1956). The effect of certain vitamin deficiencies on glycine biosynthesis. Biochemical Joumal 62, 190-198.

Bonham, J. R., Rattenbury, J. M., Meeks, A. \& Pollitt, R. J. (1989). Pyroglutamicaciduria from vigabatrin. Lancet i, 1452-1453.

Bonsnes, R. W. \& Taussky, H. H. (1945). On the colorimetric determination of creatinine by Jaffe's reaction . Joumal of Biological Chemistry 158, 581-584.

Branda, R. F. \& Eaton, J. W. (1978). Skin colour and nutrient photolysis: an evolutionary hypothesis. Science 201, 625-626.

Chanarin, I., Rothman, D., Ward, A. \& Perry, J. (1968). Folates status and requirements in pregnancy. British Medical Journal ii, 390-394.

Chmielewska, I., Bulhak, B. \& Toczko, K. (1967). Diketopiperazines and pyroglutamic acid utilization in the human organism. Bulletin de l'Academie Polonaise des Sciences 12, 719-721.

Committee on Medical Aspects of Food Policy (1991). Dietary Reference Values for Food Energy and Nutrients for the United Kingdom. Report on Health and Social Subjects no. 41. London: H.M. Stationery Office.

de Benoist, B., Jackson, A. A., Hall, J. S. E. \& Persaud, C. (1985). Whole-body protein turnover in Jamaican women during normal pregnancy. Human Nutrition: Clinical Nutrition 39C, 167-179.

Department of Health (1992). Folic Acid and the Prevention of Neural Tube Defects: Report from an Expen Advisory Group, Abstr. London: H.M. Stationery Office.

di Ilio, C., del Boccico, G., Casalone, E., Aceto, A. \& Sacchetta, P. (1986). Activities of enzymes associated with the metabolism of glutathione in fetal rat liver and placenta. Biology of the Neonate 49, 96-101.

di Ilio, C., Sacchetta, P., del Boccico, G. \& Polidoro, G. (1985). Glutathione-related enzymes in pregnant rat liver. Experientia 41, 66-67.

Duff, E. M. W. \& Cooper, E. S. (1994). Neural tube defects in Jamaica following Hurricane Gilbert. American Joumal of Public Health 84, 473-476.

Duff, E. M. W., Cooper, E. S., Danbury, C. M., Johnson, B. E. \& Serjeant, G. R. (1991). Neural tube defects in hurricane aftermath. Lancet 337, 120-121.

Food and Agriculture Organization/World Health Organization/United Nations University (1985). Energy and Protein Requirements. WHO Technical Report Series no. 552. Geneva: WHO.

Forrester, T., Badaloo, A. V., Persaud, C. \& Jackson, A. A. (1994). Urea production and salvage during pregnancy in normal Jamaican women. American Journal of Clinical Nutrition 60, 341-346.

Gersovitz, M., Bier, D., Matthews, D., Udall, J., Munro, H. \& Young. V. R. (1980). Dynamic aspects of whole body glycine metabolism: influence of protein intake in young adult and elderly males. Metabolism 29, 1087-1094.

Ghauri, F. Y. K., Mclean, A. E. M., Beales, D., Wilson, I. D. \& Nicholson, J. K. (1993). Induction of 5oxoprolinuria in the rat following chronic feeding with $N$-acetyl 4 -aminophenol (paracetamol). Biochemical Pharmacology 46, 953-957.

Hall, J. S. (1990). Zinc status during pregnancy in Jamaican women. MD Thesis, University of Sheffield.

Herbert, V., Colman, N., Spivack, M., Ocasio, E., Ghanta, V., Kimmel, K. \& Scott, T. (1975). Folic acid deficiency in the United States. Folates assay in prenatal clinic. American Joumal of Obstetrics and Gynecology 123, $175-189$.

Hubbard, B. M. (1964). The role of folic acid in pregnancy. Journal of Obstetrics and Gynaecology of the British Commonwealth 71, 529-542.

Hytten, F. E. \& Chyne, G. A. (1971). The amino aciduria of pregnancy. Journal of Obstetrics and Gynaecology of the British Commonwealth 79, 424-432.

Jablonski, N. G. (1992). Sun, skin colour and spina bifida: an exploration of the relationship between ultraviolet light and neural tube defects. Proceedings of the Australasian Society for Human Biology 5, 455-462.

Jackson, A. A. (1991). The glycine story. European Journal of Clinical Nutrition 4, 59-65.

Jackson, A. A., Badaloo, A. V., Forrester, T., Hibbert, J. M. \& Persaud, C. (1987). Urinary excretion of 5oxoproline (pyroglutamic aciduria) as an index of glycine insufficiency in normal man. British Journal of Nutrition 58, $207-214$. 
Jackson, A. A., Persaud, C., Meakins, T. S. \& Bundy, R. (1996). Increased urinary excretion of 5-L-oxoproline (pyroglutamic acid) in normal adults consuming vegetarian or low protein diets. Journal of Nutrition 126 (In the Press).

Jackson, A. A., Shaw, J. C. L., Barber, A. \& Golden, M. H. N. (1981). Nitrogen metabolism in preterm infants fed human donor breast milk: the possible essentiality of glycine. Pediatric Research 15, 1454-1461.

Kitkay, D. Z. \& Harbot, R. A. (1975). Iron and folic acid deficiency in pregnancy. Clinics in Perinatology 2 , 225-230.

Laidlaw, S. A. \& Kopple, J. D. (1987). Newer concepts of the indispensable amino acids. American Journal of Clinical Nutrition 46, 593-605.

Landman, J. P. \& Hall, J. S. (1988). Dietary patterns and nutrition in pregnancy in Jamaica. Journal of Tropical Pediatrics 35, 10-15.

Larsson, A. (1981). 5-Oxoprolinuria. In Transport and Other Inborn Errors Related to the $\gamma$-Glutamyl Cycle. Transport and Inherited Diseases, p.277-306. [C. Toothill, editor]. Lancaster: MTP Press.

Lund, P. (1984). UV-method with glutaminase and glutamate dehydrogenase. In Methods in Enzymology vol. 7, Metabolites 3. Lipids, Amino Acids and Related Compounds, pp. 357-363 [H. U. Bergmeyer, editor] Oxford: Oxford Press.

McClelland, I. S. M., \& Jackson, A. A. (1996). Urea kinetics in healthy young women: minimal effect of stage of menstrual cycle, contraceptive pill and protein intake. British Joumal of Nutrition 76, 199-209.

McClelland, I. S. M., Persaud, C. \& Jackson, A. A. (1997). Urea kinetics in healthy women during normal pregnancy. British Journal of Nutrition 77, 165-181.

McPartlin, J., Halligan, A., Scott, J. M., Darling, M. \& Weir, D. G. (1991). Accelerated folate breakdown in pregnancy. Lancet 341, 148-149.

McPherson, H. T. \& Slater, J. S. (1959). $\gamma$-amino- $n$-butyric, aspartic, glutamic and pyrrolidone carboxylic acid, and their determination and occurrence in grass conservation. Biochemical Journal 71, 654-660.

Meister, A. (1974). The $\gamma$-glutamyl cycle. Disease associated with specific enzyme deficiencies. Annals of Internal Medicine 81, 247-253.

MRC Vitamin Study Research Group (1991). Prevention of neural tube defects: results of the Medical Research Council Vitamin Study. Lancet 338, 131-136.

Neuberger, A. (1981). The metabolism of glycine and serine. Comprehensive Biochemistry 19A, 257-303.

Oberholzer, V. G., Wood, C. B. S., Palmer, T. \& Harrison, B. M. (1975). Increased pyroglutamic acid levels in patients on artificial diets. Clinical Chemistry, 62, 299-304.

Persaud, C. \& Jackson, A. A. (1991). 5-Oxoprolinuria and glycine insufficiency. Clinical Chemistry 37, 1660-1661

Persaud, C., McDermott, J., de Benoist, B. \& Jackson, A. A. (1989). The excretion of 5-oxoproline in urine as an index of glycine status, during normal pregnancy. British Journal of Obstetrics and Gynaecology 96, $440-444$.

Pitt, J. J. (1990). Association between paracetamol and pyroglutamic aciduria. Clinical Chemistry 36, $173-174$.

Pitt, J. J., Brown, G. K., Clift, V. \& Christodoulou, J. (1990). Atypical pyroglutamic aciduria: possible role of paracetamol. Journal of Inherited Metabolic Diseases 13, 755-756.

Quick, A. (1931). The conjugation of benzoic acid in man. Journal of Biological Chemistry 92, 65-85.

Ramakrishna, M., Krishnaswamy, P. R. \& Rajagopal Rao, D. (1970). Metabolism of pyrrolidonecarboxylic acid in the rat. Biochemical Journal 118, 895-897.

Shinka, T., Inoue, Y., Kuhara, T., Matsumoto, M. \& Matsumoto, I. (1985). Benzoylalanine: detection and identification of an alanine conjugate with benzoic acid in hyperammonemic patients treated with sodium benzoate. Clinica Chimica Acta 151, 293-300.

Taggart, N. (1977). Food habits in pregnancy. Proceedings of the Nutrition Society 20, 35-40.

Thompson, G. N. \& Halliday, D. (1992). Protein tumover in pregnancy. European Journal of Clinical Nutrition 46, $411-417$.

van der Werf, P. \& Meister, A. (1975). The metabolic formation and utilization of 5-L-oxoproline (Lpyroglutamate, L-pyrolidone carboxylate). Advances in Enzymology 43, 519-566.

van der Werf, P., Stephani, R. \& Meister, A. (1974). Accumulation of 5-oxoproline in mouse tissue after inhibition of 5-oxoprolinase and administration of amino acids: evidence for function of the $\gamma$-glutamyl cycle. Proceedings of the National Academy of Sciences USA 71, 1026-1029.

Walraff, E. B., Brodie, E. C. \& Bordon, A. L. (1950). Urinary excretion of amino acids in pregnancy. Journal of Clinical Investigation 29, 1542-1544.

Widdowson, E. M., Southgate, D. A. T. \& Hey, E. M. (1979). Body composition of the fetus and infant. In Nutrition and Metabolism of the Fetus and Infant, pp. 169-177 [H. A. K. Visser, editor]. The Hague: Martinus Nijhoff.

Yu, Y. M., Yang, R. D., Matthews, D. E., Wen, Z. M., Burke, J. F., Bier, D. M. \& Young, V. R. (1985). Quantitative aspects of glycine and alanine nitrogen metabolism in postabsorptive young men: effect of level of nitrogen and dispensable amino acid intake. Journal of Nutrition 115, 399-410. 